\title{
Teaching strategies predict instructors' perceptions of their effectiveness in engaging students in introductory physics for life sciences courses
}

\author{
Ellen Altermatt $\odot,{ }^{1}$ Raluca Teodorescu, ${ }^{2}$ and Ellen R. Iverson ${ }^{1}$ \\ ${ }^{1}$ Science Education Resource Center (SERC), Carleton College, Northfield, Minnesota 55057, USA \\ ${ }^{2}$ Science, Engineering and Technology Unit, Montgomery College, Takoma Park, Maryland 20912, USA
}

(Received 2 May 2021; accepted 9 September 2021; published 8 November 2021)

\begin{abstract}
Introductory physics for life sciences (IPLS) courses have emerged as a type of physics course within the introductory courses sequence. The interdisciplinary aspects of these courses as well as the diverse student populations that they serve create significant challenges for instructors who choose to design and deliver them. The Living Physics Portal is a collaborative project, funded by the National Science Foundation, that is designed to support instructors involved in teaching IPLS courses. As part of the project, a survey was administered to document current pedagogical beliefs and practices in teaching IPLS courses. On this survey, 383 instructors (out of 762 respondents) reported that they had taught an IPLS course in the past two years. We analyzed instructor perceptions about the effectiveness of their IPLS courses in engaging students and examined predictors of differences in their perceived course effectiveness. Descriptive statistics showed that there is considerable variability in instructors' perceptions of the degree to which their courses are effective in engaging students. Hierarchical linear regression analyses identified self-reported teaching strategies as independent predictors of perceived course effectiveness, even after controlling for prior teaching experience and community of practice self-perceptions. We present our results and discuss implications for the IPLS community.
\end{abstract}

DOI: 10.1103/PhysRevPhysEducRes.17.020133

\section{INTRODUCTION}

Over the last decade, introductory physics for life sciences (IPLS) courses have emerged as a type of physics course within the introductory physics courses sequence [1-3]. These courses answer national calls to reform physics instruction to better equip future physicians, biologists, or health-care professionals in physics principles, theoretical relationships involving experiments and modeling, and the behavior of dynamical systems [4-8]. Such courses focus on developing scientific competencies, such as quantitative principles and models that rely on physical techniques [6] in interdisciplinary contexts $[9,10]$. As compared with other kinds of physics courses, the design of IPLS courses is challenging due to the diversity of life sciences fields that could be addressed including molecular biology, pharmacology, medicine, ecology, evolutionary biology, physical therapy, occupational therapy, and exercise physiology. The physics instruction needed by these fields, taken collectively, is far beyond what can be

Published by the American Physical Society under the terms of the Creative Commons Attribution 4.0 International license. Further distribution of this work must maintain attribution to the author(s) and the published article's title, journal citation, and DOI. taught in a one-year course [6,11]. Thus, it is not possible to create one course that would satisfy the needs of all life sciences students. Instructors are challenged to design physics courses tailored to the needs of their specific life sciences student population.

In 2014, the American Association of Physics Teachers (AAPT), with support from the National Science Foundation (NSF), organized a conference that brought together instructors teaching IPLS courses to discuss content and teaching strategies and to make recommendations related to IPLS courses. Among the nine recommendations, the executive summary of the conference report [11] lists the following two that are critical to this study:

- IPLS courses should be based on best pedagogical practices, and

- Reform work should be supported via an online database of IPLS curricular resources and assessments, and an online community that supports IPLS instructors should be created.

The Living Physics Portal [12] was designed to address these recommendations by creating an online, open-source, peer-reviewed, and innovatively structured environment for developing and disseminating instructional materials for IPLS courses. It was developed with NSF support, and it is a collaboration between nine colleges and universities and the AAPT. The Living Physics Portal allows contributors to submit their work for peer review, evaluation, and inclusion 
and serves as both a curricular library and a dissemination site. It includes a course-building interface that allows instructors to create innovative and individualized courses adapted to their needs, mixing and matching from multiple sources. This portal facilitates professional development, helping faculty to learn how to use the portal and its materials and to contribute to it through documents, workshops, interactive communities, and social networks. It is informed by research on (i) usability testing, (ii) course design, and (iii) professional development.

\section{A. Teaching strategies and student engagement}

The current study was designed to support Living Physics Portal project leaders and the broader IPLS and physics education research (PER) communities by improving our understanding of how teaching strategies impact student engagement in IPLS courses. There is ample evidence that student engagement in the classroom is essential in supporting student performance [13-15] and physics educators have been among the pioneers in designing, adopting, and adapting learning strategies and environments to foster engagement by shifting from instructor-centered instruction to student-centered instruction [16-20]. Importantly, however, the research on student engagement in the context of IPLS courses is still in its infancy. Previous research focusing on students' perspectives on their engagement found that students engage more deeply with environments that foster a sense of coherence or have personal meaning to them [21]. Our study contributes to this nascent body of work on student engagement in IPLS courses by examining the impact of specific lab and lecture teaching strategies on instructors' perceptions of the effectiveness of their courses in engaging students majoring in life science disciplines. The lab and lecture teaching strategies that are the focus of this study were identified in collaboration with Living Physics Portal project leaders. Additionally, these strategies align with those reported on a survey administered prior to the Conference on Introductory Physics for the Life Sciences [11], (p. 33). Notably from the preconference survey, some attendees who planned to teach an IPLS course in the future stated that they wanted to learn more about "what has worked or not worked" [11], (p. 34). The current study begins to address this call by examining instructors' perceptions of effective teaching strategies.

\section{B. Research questions}

Our study was guided by four research questions:

RQ1. What teaching strategies are instructors using in the lab and "lecture" portions of their IPLS courses?

RQ2. To what degree do instructors believe that their introductory physics courses, as currently taught, are effective in engaging students majoring in life science disciplines?

RQ3. Do instructors' self-reported teaching strategies in the lab portions of their courses predict their perceived course effectiveness in engaging students?

RQ4. Do instructors' self-reported teaching strategies in the "lecture" portions of their courses predict perceived course effectiveness in engaging students?

Importantly, the survey relied on instructors' selfreported teaching strategies and own interpretations of student engagement. As discussed in the limitations section of this article, we acknowledge that different instructors might interpret the word "engagement" differently. Likewise, instructors' self-reports of their teaching strategies may differ from actual strategies and instructors' perceptions of student engagement may differ from student perceptions of their own engagement.

Although future work will be important in validating instructors' perceptions (by, for example, determining whether instructor perceptions of effectiveness correlate with students' or outside observers' perceptions of effectiveness and engagement), the current study is important in its own right given ample evidence that instructor beliefs are associated with teaching practices and, in turn, student outcomes $[22,23]$. For example, when instructors report high levels of teaching self-efficacy, they report being more committed to teaching, more likely to engage with unfamiliar topics, more willing to learn about and experiment with new pedagogical methods to better meet the needs of their students, and more inclined to spend time working closely with struggling students [24]. These characteristics are, in turn, associated with motivation to improve teaching $[25,26]$ and student academic adjustment [23].

\section{METHODS}

\section{A. The survey}

In 2019, Living Physics Portal project leaders and the authors collaboratively designed an online survey for physics faculty to document current pedagogical beliefs and teaching practices in IPLS courses. The survey was informed by the Conference on Introductory Physics for the Life Sciences Report [11] and consisted of 24 items, divided into three sections:

1) Instructional responsibilities

2) Perspectives on teaching physics to life science students

3) Demographics

After providing informed consent, all survey participants were asked to respond to items related to instructional responsibilities and demographics. Items in the first section served as conditional branching for items in the second section such that items in the second section were only presented to faculty who reported teaching an introductory 
physics course in which a "substantial portion of the enrolled students are majoring in life science disciplines (e.g., biology and pre-health)." The third section was a stand-alone section.

Within the first and second sections, respondents were asked to

- indicate their level of prior teaching experience,

- rate their self-perceptions of belongingness to a community of practice,

- report on their teaching strategies for the lab and "lecture" portions of their courses, and

- rate the perceived effectiveness of their course in engaging students majoring in life science disciplines.

Items that are the focus of the current study are described briefly here. The full survey is included in the Supplemental Material [27].

Teaching experience.-Survey respondents were asked to indicate their level of prior experience teaching IPLS courses by responding to a single item (i.e., "During how many academic terms have you taught an introductory physics course in which a substantial portion of the enrolled students are majoring in life science disciplines?"). Respondents used a six-point scale ranging from 1 ("one") to 6 ("six or more").

Self-perceptions of belongingness to a community of practice.-Survey respondents were asked to indicate their self-perceptions of belonginess to a community of practice by responding to a single item (i.e., "To what extent do you feel you are a part of a community of faculty who are working to reform how introductory physics is taught to students who are majoring in life science disciplines?"). Respondents used a five-point scale where $1=$ "not at all", 2 = "a little", 3 = "a moderate amount", $4=$ "a lot", and $5=$ "a great deal".

Teaching strategies in lab portion of course.-Survey respondents were asked to report on the teaching strategies they used in the lab portion of their courses by indicating the frequency with which they used three instructional approaches in their introductory physics course with substantial life science enrollment:

1) ask students to design their own experiments

2) employ instructional techniques that are inquiry based

3) select activities that are relevant to life science disciplines (e.g., biology and health).

Respondents used a five-point scale where 1 = "never", 2 = "rarely", 3 = "about half the time", $4=$ "in nearly every lab", and $5=$ "in every lab".

Teaching strategies in lecture portion of course.Survey respondents were asked to report on the teaching strategies they used in the lecture portion of their courses by indicating the frequency with which they used six instructional approaches in their introductory physics course with substantial life science enrollment:
1) employ instructional techniques that promote active learning (e.g., small group discussions; in-class exercises)

2) explicitly address the anxiety that students may have about physics courses

3) avoid mathematically sophisticated examples or problems (e.g., those that require calculus)

4) include planned or "just-in-time" mathematics instruction

5) connect course materials to "real-world" issues

6) cover topics that are relevant to life science disciplines (e.g., biology and health).

Respondents used a five-point scale where $1=$ "never", $2=$ "rarely", $3=$ "about half the time", $4=$ "in nearly every class", and $5=$ "in every class". Lecture was included in quotation marks to be inclusive of respondents who use active learning in their courses.

Perceived course effectiveness. - Survey respondents were asked to rate the perceived effectiveness of their course in engaging students majoring in life science disciplines by responding to a single item (i.e., "To what degree do you believe your introductory physics course, as currently taught, is effective in engaging students majoring in life science disciplines?"). Respondents used a five-point scale where $1=$ "not effective at all", 2 = "slightly effective", $3=$ "moderately effective", $4=$ "very effective", and 5 = "extremely effective".

In October 2019, AAPT administered the survey by distributing unique survey links via email to five groups of participants:

- members of the Division of Biological Physics (DBIO) of the American Physical Society (APS) $(n=2193)$

- members of the Forum on Education (FEd) division of the American Physical Society (APS) $(n=4308)$

- members of the American Association of Physics Teachers (AAPT) $(n=2913)$

- individuals who had participated in events (e.g., workshops) related to the development of the Living Physics Portal website or who had registered for the website $(n=458)$

- college and university faculty who were identified as department chairs by the American Institute of Physics (AIP) $(n=755)$. Department chairs were asked to distribute the survey link to members of their department. The number of faculty who received a link to the survey using this method is unknown.

The survey remained open for approximately three weeks.

\section{B. Participants}

A total of 762 instructors completed the survey. As shown in Fig. 1, the number of participants varied by distribution group, with participants who responded to the 
Number of participants (response rate)

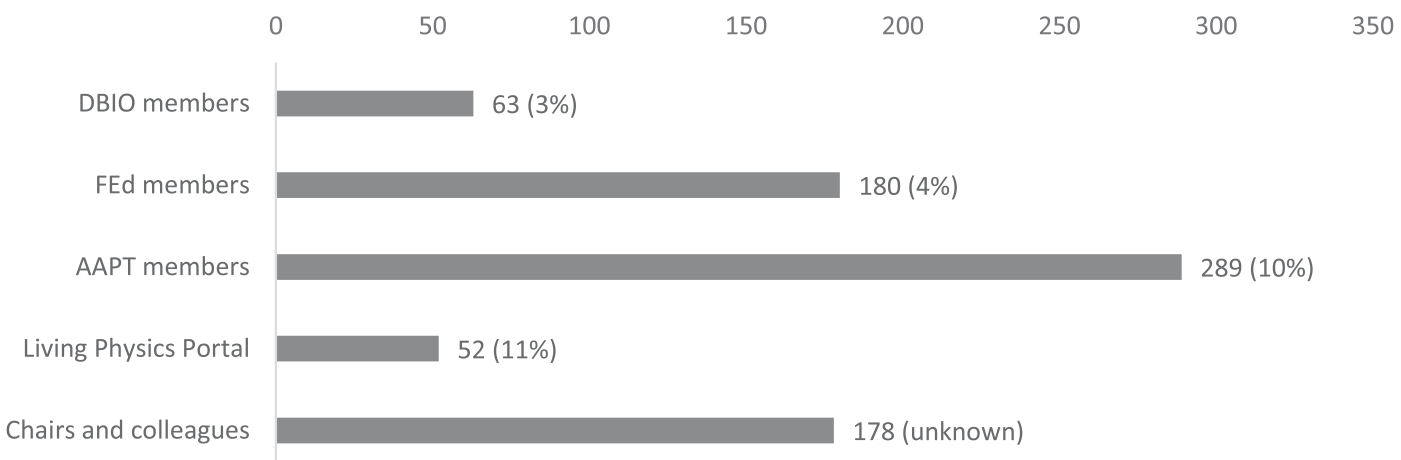

FIG. 1. Number of participants who completed the survey and response rates by distribution group.

survey link sent to AAPT members comprising $38 \%$ of the sample. Response rates are included in parentheses, but these rates should be interpreted with some caution as there was overlap in the memberships of the five groups. For example, many AAPT members are also members of the Forum on Education (FEd) division of the American Physical Society.

The majority of respondents (94\%) reported teaching at a four-year college or university that offered baccalaureate $(41 \%)$, master's $(10 \%)$, or doctoral $(43 \%)$ degrees. The majority (73\%) also reported holding the rank of assistant professor (15\%), associate professor $(22 \%)$, or professor (36\%). Most respondents (88\%) reported regularly teaching in a physics department. The majority of respondents were male (71\%) and White $(74 \%)$. These demographic data are consistent with those reported by the American Association of Physics Teachers (AAPT) and the American Physical Society (APS). ${ }^{1}$

Preliminary analyses of survey data indicated that $50 \%$ of the full sample (i.e., 383 of 762 respondents) reported that they had, in the past two years, taught an introductory physics course in which a "substantial portion of the enrolled students are majoring in life science disciplines (e.g., biology and pre-health)." Given the goal of the current study to focus on predictors of perceived effectiveness of these courses, all subsequent analyses are limited to this subsample of 383 participants.

\footnotetext{
${ }^{1}$ As noted in the 2017 Report on Supporting and Enhancing Diversity and Inclusiveness, among AAPT members who reported on their gender (32\%), 78.1\% identified as male. Among AAPT members who reported on their race or ethnicity $(27 \%)$, $85.6 \%$ identified as White. In a 2019 membership unit profile report, among DBIO and FEd members who reported on their gender, $71.4 \%$ of DBIO members and $78.7 \%$ of FEd members identified as male.
}

\section{Analysis plan}

Descriptive statistics (e.g., means, standard deviations) were used to answer the first two research questions. Hierarchical linear regression analyses were used to answer the third and fourth research questions. ${ }^{2}$ Hierarchical linear regression is a form of multiple linear regression. Multiple linear regression is a statistical technique that attempts to model the relationship between two or more predictor variables and an outcome variable. Hierarchical linear regression extends the principles of multiple linear regression by building and comparing successive linear regression models, each with more predictors. At each step in the model an $\mathrm{R}^{2}$ value is produced that indicates the proportion of the variance in the outcome variable (here, perceived course effectiveness) that is explained by the predictor variables after holding other predictors in the model constant. ${ }^{3} \mathrm{R}^{2}$ values can be compared across steps to determine whether the addition of new predictor variables leads to a statistically significant improvement in the model's ability to predict the outcome variable.

As a precursor to the hierarchical linear regression analyses, bivariate correlations were examined among all survey items to identify potential predictors and confounding variables. These analyses indicated that instructors' self-reported teaching experience and selfperceptions of belongingness to a community of practice were correlated with both teaching strategies and effectiveness ratings. As a result, these variables were included

\footnotetext{
${ }^{2}$ These approaches were chosen given evidence that parametric tests are robust-and may, in fact, be more robust than non-parametric tests-for Likert scale data [28-30]. Nonparametric versions of these analysis procedures yielded similar findings.

${ }^{3} \mathrm{R}^{2}$ values can range from 0 to 1 . In the behavioral sciences, $\mathrm{R}^{2}$ values of $0.02,0.13$, and 0.26 are considered "small," "medium," and "large" respectively [31].
} 
TABLE I. Descriptive statistics for predictor variables.

\begin{tabular}{|c|c|c|c|}
\hline Predictor variable & $n$ & Range of responses & Mean (SD) \\
\hline 1. Teaching experience & 381 & $1-6$ & $4.95(1.71)$ \\
\hline 2. Self-perceptions of belongingness to community of practice & 355 & $1-5$ & $2.47(1.20)$ \\
\hline $\begin{array}{l}\text { 3a. Teaching strategies in lab portion of course } \\
\text { Students design experiments } \\
\text { Instruction is inquiry-based } \\
\text { Activities are relevant to life science disciplines }\end{array}$ & $\begin{array}{l}331 \\
331 \\
331\end{array}$ & $\begin{array}{l}1-5 \\
1-5 \\
1-5\end{array}$ & $\begin{array}{ll}2.01 & (0.99) \\
3.33 & (1.25) \\
2.38 & (1.00)\end{array}$ \\
\hline $\begin{array}{l}\text { 3b. Teaching strategies in lecture portion of course } \\
\text { Instruction promotes active learning } \\
\text { Instructor addresses anxiety about physics courses } \\
\text { Instructor avoids mathematically sophisticated examples or problems } \\
\text { Planned or just-in-time mathematics instruction is included } \\
\text { Course materials connect to real-world issues } \\
\text { Topics are relevant to life science disciplines }\end{array}$ & $\begin{array}{l}358 \\
357 \\
358 \\
356 \\
357 \\
358\end{array}$ & $\begin{array}{l}1-5 \\
1-5 \\
1-5 \\
1-5 \\
1-5 \\
1-5\end{array}$ & $\begin{array}{l}4.04(1.13) \\
3.04(1.03) \\
3.75(1.18) \\
2.85(1.11) \\
3.59(0.89) \\
2.98(0.93)\end{array}$ \\
\hline
\end{tabular}

as predictors in step 1 and step 2 of the models, respectively. At step 1, the models examine the independent effect of teaching experience on perceived course effectiveness. At step 2, the models examine the effect of community of practice beliefs on perceived course effectiveness after controlling for the effect of teaching experience. Teaching strategies were entered at step 3. This approach allows us to determine whether teaching strategies predict perceived course effectiveness over and above (i.e., after controlling for) the effects of teaching experience and self-perceptions of belongingness to a community of practice.

\section{RESULTS}

RQ1. What teaching strategies are instructors using in the lab and lecture portions of their IPLS courses?

In Table I, we present descriptive statistics for all the predictor variables used in this study: teaching experience, self-perceptions of belongingness to community of practice, and teaching strategies used in the lab and lecture portion of the course. $N$ 's vary because some respondents failed to answer some questions and because 24 respondents indicated that their introductory physics course did not have a lab.

On average, respondents reported that they had taught an introductory physics course in which a substantial portion of the enrolled students were majoring in life science disciplines for nearly five terms. As group, however, respondents indicated they felt only "a little" or "a moderate amount" that they were part of a community of faculty who are working to reform how introductory physics is taught to students who are majoring in life science disciplines. In the lab portion of their courses, respondents reported that they were most likely to provide inquiry-based instruction (with the mean rating between "about half the time" and "in nearly every lab") and least likely to ask students to design their own experiments (with the mean rating nearest to rarely). In the lecture portion of courses, respondents were most likely to indicate that they provided instruction that promoted active learning (with the mean rating nearest to "in nearly every class"). They were least likely to report that they included planned or "just-in-time" mathematics instruction (with the mean rating between rarely and about half the time).

RQ2. To what degree do instructors believe that their introductory physics courses, as currently taught, are effective in engaging students majoring in life science disciplines?

As shown in Fig. 2, although nearly half of participants viewed their course as "moderately effective," there was considerable variability in respondents' ratings (mean = $3.29, \mathrm{SD}=0.85, n=363$ ), with $38 \%$ percent of the sample rating their course as "very effective" or "extremely effective," and $14 \%$ rating their course as "slightly effective" or "not effective at all."

From Table I, it is evident that inquiry is a predominant teaching strategy in the lab portion of many IPLS courses while active learning is a predominant teaching strategy in the lecture portion of many IPLS courses. Because both of these teaching strategies rely heavily on students' engagement, we used hierarchical linear regression to better understand whether differences in self-reported teaching strategies might help to explain some of the variability in instructors' perceptions of engaging students majoring in life sciences disciplines in their IPLS courses.

RQ3. Do instructors' self-reported teaching strategies in the lab portions of their courses predict their perceived course effectiveness in engaging students? 


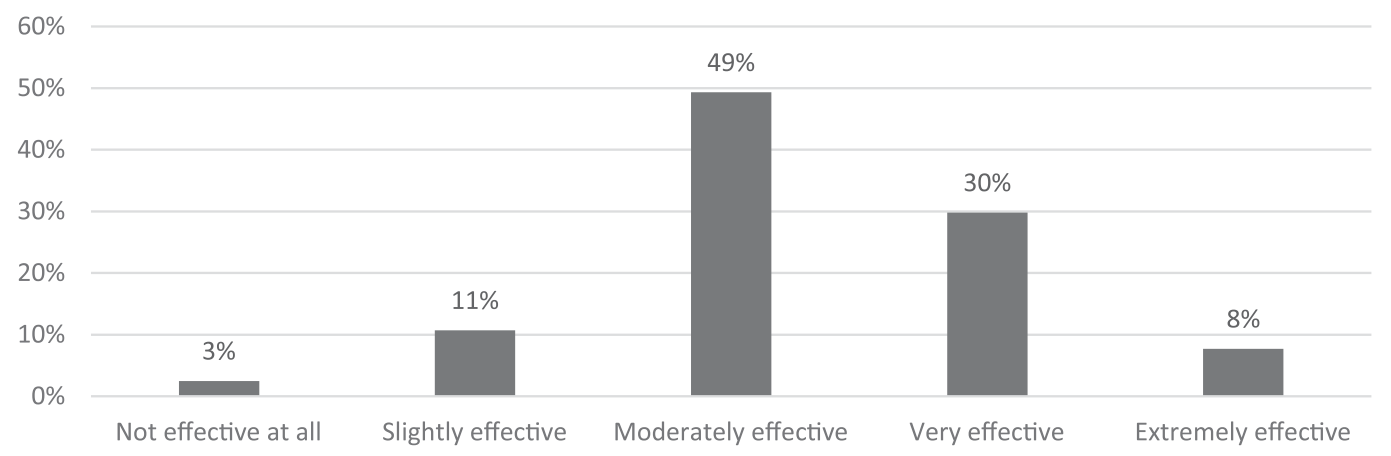

FIG. 2. Frequency distribution of perceived course effectiveness in engaging students majoring in life science disciplines.
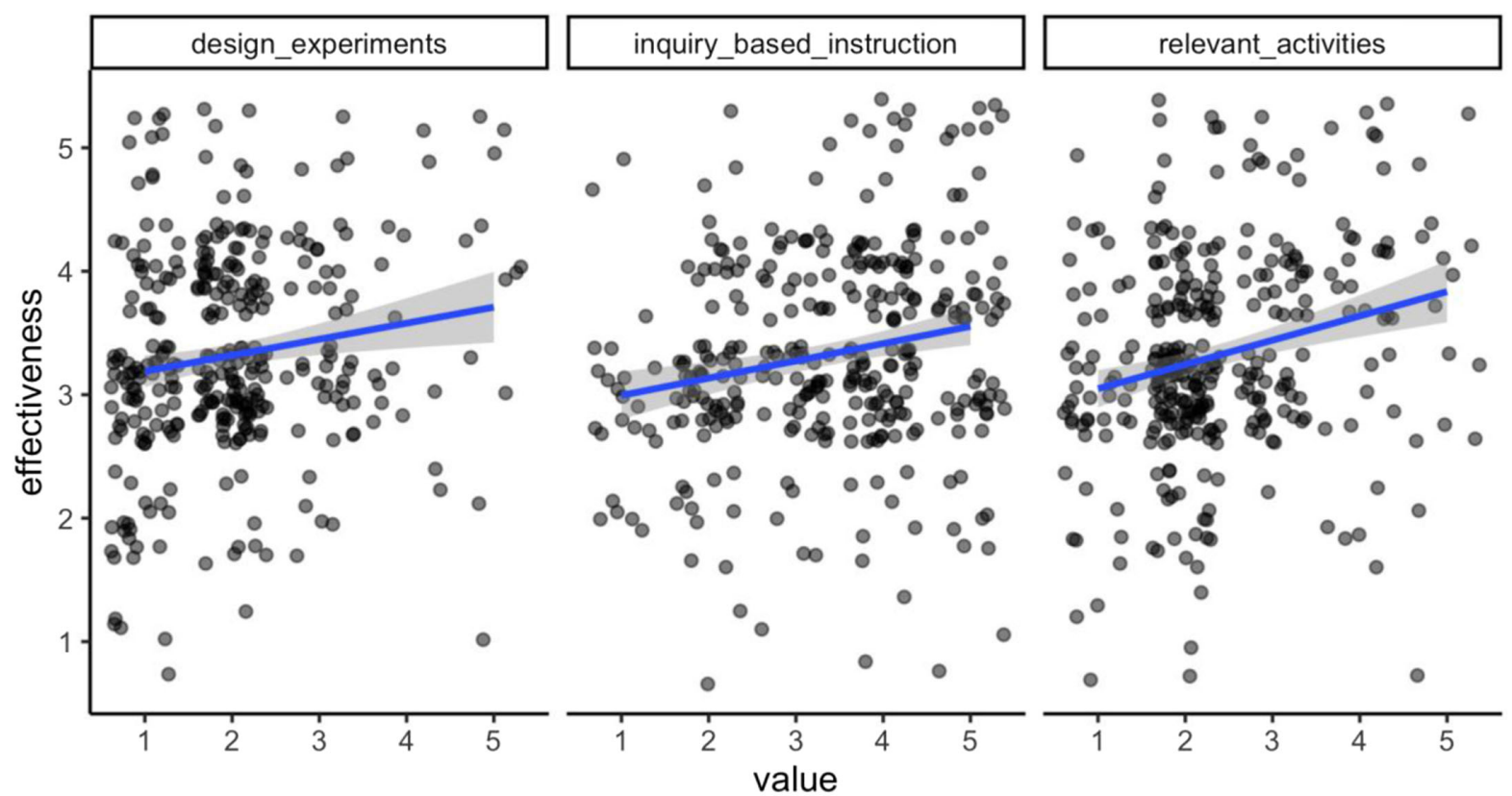

FIG. 3. Associations between laboratory teaching strategies and perceived course effectiveness in engaging students.

To answer this question, we, first, visualized the data by plotting response values for each of the laboratory teaching strategy variables on the $x$ axis (where $1=$ "never" and $5=$ "in every class") and perceived course effectiveness in engaging students majoring in life science disciplines on the $y$ axis (where $1=$ "not effective at all" and $5=$ "extremely effective"). A small amount of random "noise" was added to each of the data points using the "jitter" function in $\mathrm{R}$ to avoid overplotting. ${ }^{4}$ Linear

\footnotetext{
${ }^{4}$ Overplotting occurs when data or labels in a data visualization overlap, making it difficult to see individual data points in a data visualization. R's jitter function adds a small amount of random variation to the location of each point to reduce overlap. In Figs 3 and 4, darker dots indicate that there is more overlap of data points; lighter dots indicate that there is less (or no) overlap of data points.
}

regression lines with a ribbon representing standard errors are shown in blue. As shown in Fig. 3, all three laboratory teaching strategies (i.e., students design experiments, instruction is inquiry based, activities are relevant to life science disciplines) showed positive linear associations with perceived course effectiveness.

Hierarchical linear regression analyses were used to explore these associations further. The outcome variable was perceived course effectiveness. Predictor variables were entered in steps. Specifically, teaching experience was entered at step 1. Self-perceptions of belonginess to a community of practice was entered at step 2. Selfreported laboratory teaching strategies were entered at step 3. Results are summarized in Table II.

As expected, when entered alone in step 1 of the model, teaching experience predicted higher levels of perceived course effectiveness, $\beta=0.14, t(325)=2.56, p<0.01$ 
TABLE II. Summary of hierarchical regression analyses predicting perceived course effectiveness from teaching experience, selfperceptions of belongingness to community of practice, and teaching strategies in lab portion of course.

\begin{tabular}{lcc}
\hline \hline Predictor variable & Step 1 & Step 2 \\
\hline 1. Teaching experience & $0.14^{* *}$ & $0.12^{*}$ \\
2. Self-perceptions of belongingness to community of practice & & $0.13^{*}$ \\
3a. Teaching strategies in lab portion of course & & $0.23^{* * *}$ \\
Students design experiments & & 0.00 \\
Instruction is inquiry-based & & 0.10 \\
Activities are relevant to life science disciplines & & $0.14^{* *}$ \\
$R^{2}$ & 0.02 & 0.14 \\
$R^{2}$ change & $0.02^{*}$ & 0.10 \\
\hline \hline
\end{tabular}

Numbers represent standardized regression coefficients $(\beta \mathrm{s})^{5}$ and, in the last two rows, $R^{2}$ values. $^{6}$

${ }^{*} p<0.05 .{ }^{*} p<0.01 .{ }^{* * *} p<0.001{ }^{7}$

$\left[R^{2}=0.02, F(1,325)=6.53, p<0.01\right] .{ }^{8}$ When added to the model at step 2, self-perceptions of belongingness to a community of practice also emerged as a significant, positive predictor of perceived course effectiveness, $\beta=0.28, t(324)=5.22, p<0.001$, and resulted in a statistically significant, $8 \%$ increase in the model's ability to predict course effectiveness $\left[R^{2}\right.$ change $=0.08$, $F(1,324)=27.22 p<0.001]$. Instructors' self-reported teaching strategies in the lab portion of their course were added at step 3. After controlling for the effects of other labbased teaching strategies, selecting activities that are relevant to life science disciplines predicted higher perceived course effectiveness, $\beta=0.14, t(321)=2.48$, $p<0.01$. Together, adding all three lab teaching strategies to the model contributed to a statistically significant, $4 \%$ increase in the model's ability to predict perceived course effectiveness $\left[R^{2}\right.$ change $=0.04, F(3,321)=4.92$,

\footnotetext{
${ }^{5}$ Hierarchical regression analyses produce regression coefficients that represent the degree of change in the outcome variable for every one unit change in the predictor variable. When the regression coefficients are standardized, they are often referred to as standardized beta coefficients $(\beta)$ and the unit of change is one standard deviation. The value of $\beta$ can range from 0 to 1 , with larger beta coefficients indicating a stronger relationship between the predictor and outcome variables. Because $\beta$ 's are standardized, they can be compared within a regression analysis to determine which predictor variable has the strongest relationship to the outcome variable. A $t$ test is used to determine whether the standardized beta coefficient is significantly different from zero.

${ }^{6} R^{2}$ values represent the percent of variance in the outcome variable (here, perceived course effectiveness) that is explained by the predictor variables. An $F$ test is used to determine whether $R^{2}$ change (i.e., the change in $R^{2}$ from one step to the next step) is significantly different from zero.

${ }^{7}$ The $p$ value for each standardized regression coefficient $(\beta)$ and $R^{2}$ change value tests the null hypothesis that each coefficient or value is equal to zero (no effect). A low $p$ value (typically $p<0.05$ ) indicates that the null hypothesis can be rejected.

${ }^{8}$ Footnotes in Table II provide more information on how to interpret these values.
}

$p<0.01]$. These results indicate that the strategies instructors employ in the lab portions of their courses are predictive of perceived course effectiveness, even after controlling for other key predictors of perceived course effectiveness (i.e., teaching experience and perceptions of belongingness to a community of practice).

RQ4. Do instructors' self-reported teaching strategies in the lecture portions of their courses predict perceived course effectiveness in engaging students?

To answer this research question, we first visualized the data by plotting response values for each of the lecture teaching strategy variables on the $x$ axis (where $1=$ "never" and $5=$ "in every class") and perceived course effectiveness in engaging students majoring in life science disciplines on the $y$ axis (where $1=$ not effective at all and 5 = extremely effective). Again, a small amount of random "noise" was added to each of the data points using the jitter function in $\mathrm{R}$ to avoid overplotting. Linear regression lines with a ribbon representing standard errors are shown in blue.

As shown in Fig. 4, five of the six lecture teaching strategies showed positive linear associations with perceived course effectiveness, while one (i.e., instructor avoids mathematically sophisticated examples or problems) showed a negative association with perceived course effectiveness.

Hierarchical linear regression analyses were used to explore these associations further. The outcome variable was perceived course effectiveness. Predictor variables were entered in steps. Specifically, teaching experience was entered at step 1. Self-perceptions of belongingness to a community of practice was entered at step 2 . Self-reported lecture teaching strategies were entered at step 3. Results are summarized in Table III.

As expected, when entered alone in step 1 of the model, teaching experience predicted higher levels of perceived course effectiveness, $\beta=0.15, t(347)=2.79, p<0.01$, $F(1,347)=7.80, p<0.01]$. When added to the model at step 2, self-perceptions of belongingness to a community of 

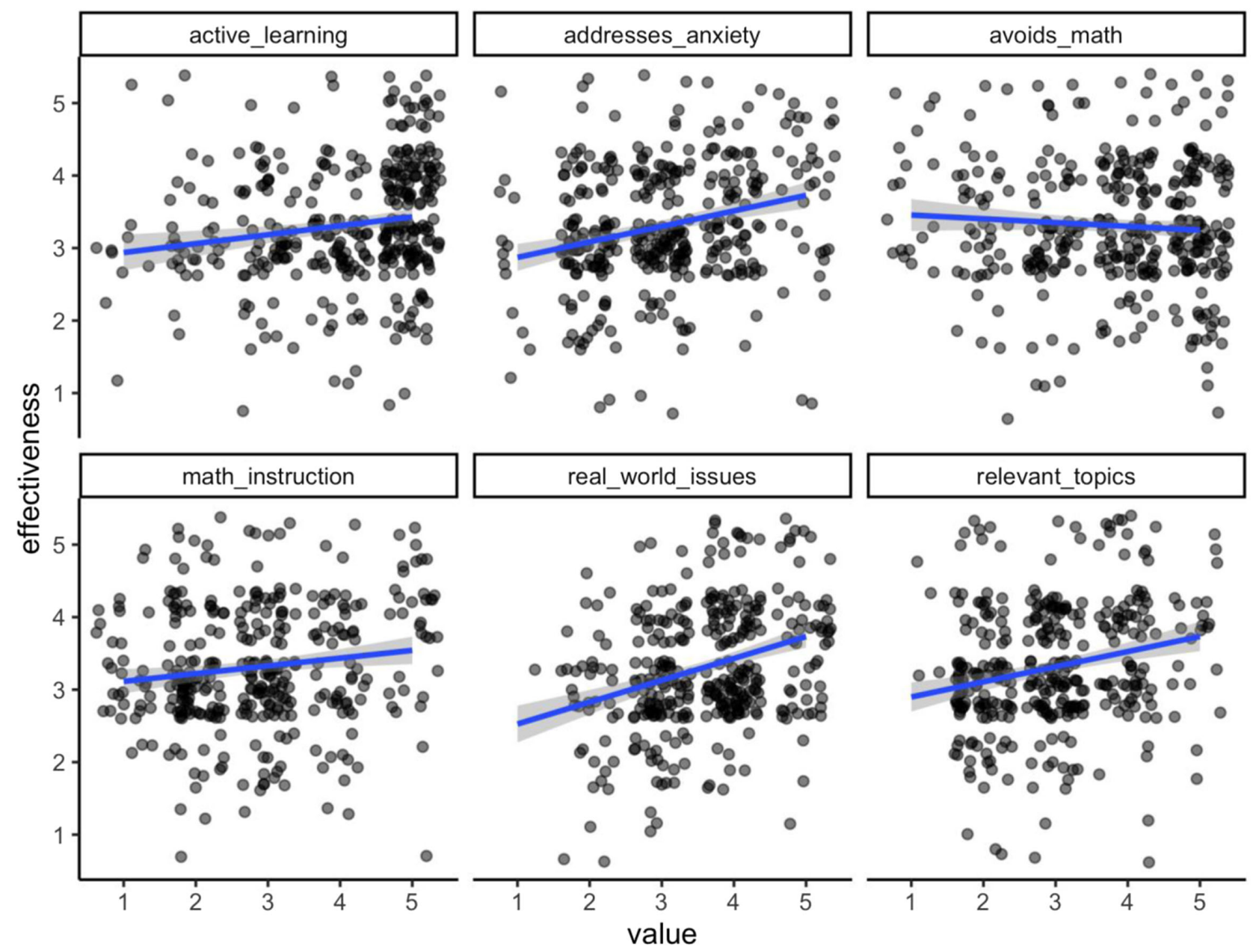

FIG. 4. Associations between lecture teaching strategies and perceived course effectiveness in engaging students.

practice also emerged as a significant, positive predictor of perceived course effectiveness, $\beta=0.29, t(346)=5.73$, $p<0.001$, and resulted in a statistically significant, $9 \%$ increase in the model's ability to predict course effectiveness $\left[R^{2}\right.$ change $\left.=0.09, F(1,346)=32.88, p<0.001\right]$. Instructors' self-reported teaching strategies in the lecture

TABLE III. Summary of hierarchical regression analyses predicting perceived course effectiveness in engaging students from teaching experience, self-perceptions of belongingness to community of practice, and teaching strategies in lecture portion of course.

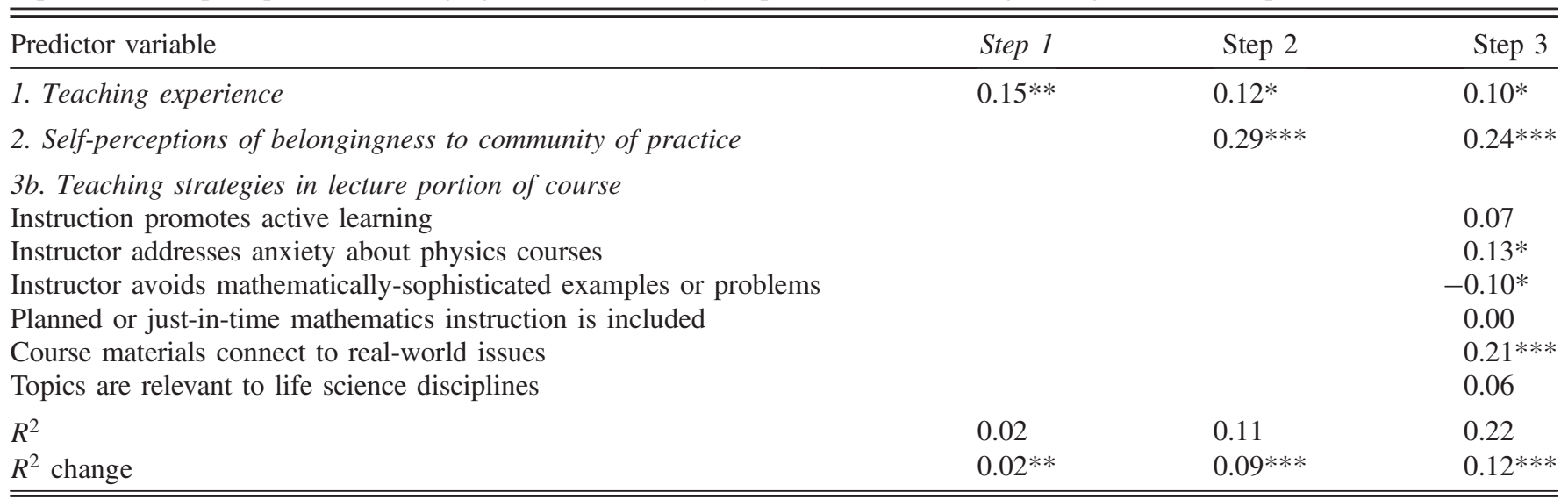

Numbers represent standardized regression coefficients $(\beta)$ and, in the last two rows, $R^{2}$ values.

${ }^{*} p<0.05 .{ }^{* *} p<0.01 .{ }^{* * *} p<0.001$. 
portion of their course were added at step 3. After controlling for the effects of other lecture-based teaching strategies, explicitly addressing the anxiety that students may have about physics courses, $\beta=0.13, t(340)=2.24$, $p<0.05$, and selecting activities that connect course material to "real-world" issues, $\beta=0.21, t(343)=3.67$, $p<0.001$, both predicted higher levels of perceived course effectiveness in engaging students. In contrast, avoiding mathematically sophisticated examples or problems (e.g., those that require calculus), predicted lower levels of perceived course effectiveness in engaging students, $\beta=0.10, t(340)=2.11, p<0.05$. Together, adding lecture teaching strategies to the model contributed to a statistically significant, $12 \%$ increase in the model's ability to predict perceived course effectiveness $\left[R^{2}\right.$ change $=0.12$, $F(1,340)=8.53, p<0.001]$. These results indicate that the strategies instructors employ in the lecture portions of their courses are predictive of perceived course effectiveness in engaging students, even after controlling for other key predictors of perceived course effectiveness (i.e., teaching experience and perceptions of belongingness to a community of practice).

\section{DISCUSSION}

Designing and delivering IPLS courses that promote student engagement is a challenging undertaking. Our research-part of the Living Physics Portal projectinvolves 383 instructors who reported that they had taught an IPLS course in the past two years. We used descriptive statistics and hierarchical regression analyses to analyze the perceptions of these instructors about the effectiveness of their IPLS courses in engaging students. The predictor variables considered were as follows:

- teaching experience

- self-perceptions of belongingness to a community of practice

- teaching strategies used in the lab portion of the course

- teaching strategies used in the lecture portion of the course.

The results of our study suggest the following:

1. There is considerable variability on all study variables including perceived course effectiveness and teaching strategies in both the lab and lecture portions of classes. These findings suggest that additional work needs to be done to ensure that more instructors feel confident in their ability to engage students majoring in life science disciplines and to ensure that these instructors have the material and personal resources and institutional support they need to engage in effective course reform.

2. Instructors with more experience teaching introductory physics to students majoring in life science disciplines are more confident that their course effectively engages these students than instructors with less experience. This finding may not be surprising, but does indicate that more experienced instructors could be an important resource for sharing effective curricular resources and pedagogical practices with the IPLS and broader PER communities. That said, it is possible that more experienced instructors are overestimating the effectiveness of their courses in engaging students in life science courses. Likewise, it is likely that less experienced instructors may be more open to and able to share novel teaching strategies that are equally or more effective. Future will work be important in testing these propositions.

3. Instructors who feel that they are part of a community of practice focused on reforming how introductory physics is taught to students who are majoring in life science disciplines are more confident that their course effectively engages these students than instructors who do not feel they are part of this community or feel less a part of this community. The community of practice effect is relatively strong (accounting for an additional 7\%$8 \%$ of the variance in perceived course effectiveness after controlling for the effects of teaching experience) suggesting that efforts to build a community of practice through efforts like the Living Physics Portal are critical.

4. Instructors who report that they more frequently select lab activities that are relevant to life science disciplines (e.g., biology and health) are more likely to indicate that their course effectively engages students majoring in life science disciplines than instructors who less frequently select these types of lab activities. Lab teaching strategies accounted for $4 \%$ of the variance in perceived course effectiveness beyond that explained by teaching experience or perceptions of belongingness to a community of practice. This finding is consistent with prior work indicating that students are more engaged when IPLS instructors make interdisciplinary connections (see Ref. [21]) and provides additional empirical evidence to support efforts to reform the ways in which introductory physics is taught to students majoring in life science disciplines.

5. Instructors who report that they more frequently connect course materials to real-world issues and who explicitly address the anxiety that students may have about physics courses in the lecture portions of their courses are more likely to indicate that their course effectively engages students majoring in life science disciplines than instructors who do so less frequently. In contrast, avoiding mathematically sophisticated examples or problems (e.g., those that require calculus) predicted lower levels of perceived course effectiveness. Lecture teaching strategies accounted for $12 \%$ of the variance in perceived 
course effectiveness beyond that explained by teaching experience or perceptions of belongingness to a community of practice. The finding regarding the importance of connecting course materials to real world issues is consistent with prior research indicating that students are more engaged when instructors use examples students perceive as authentic or that are otherwise personally meaningful (see, for example, Ref. [21]). Likewise, the finding regarding the importance of acknowledging students' anxiety is consistent with evidence that science anxiety is widespread and associated with negative outcomes (e.g., poorer academic performance and career avoidance) and can sometimes be mitigated with relatively modest interventions $[32,33]$. Both findings are, moreover, consistent with instructor and expert recommendations (see Ref. [11]) and, together, provide additional empirical evidence to support efforts to reform the ways in which introductory physics is taught to students majoring in life science disciplines. The finding that avoiding mathematically-sophisticated examples or problems predicted lower perceived course effectiveness and the finding that other teaching strategies (e.g., employing instructional techniques that promote active learning) did not independently predict course effectiveness demonstrates the importance of empirically testing propositions about the value of a range of teaching strategies to determine best practices. Empirical testing is especially important given wide variations in instructor practices as seen here and in other studies. For example, on a survey administered to participants prior to the Conference on Introductory Physics for the Life Sciences, just over $50 \%$ of respondents indicated that IPLS courses at their institution differed from courses typically taken by physics majors by being less mathematically sophisticated. Nearly half of respondents, however, indicated that this was not a difference, and more than $20 \%$ indicated that IPLS courses at their institution required calculus [11]. Future research will be important in understanding the conditions under which more mathematically-sophisticated courses can be effective (see Ref. [34]).

Future work will be important in tracking changes in IPLS teaching strategies, in student engagement in IPLS courses (as perceived by both instructors and by students), and in the associations between teaching strategies and student engagement over time.

\section{A. Limitations}

One important limitation of the current study is that the survey relied on instructors' self-reported teaching strategies in the lab and lecture portions of their courses. No data were collected on students' demographic characteristics. Likewise, no data were collected on students' perceptions of the types of teaching strategies used by their instructors or the effectiveness of these strategies. It is possible that instructors were unable or unwilling to accurately judge or report on their actual teaching strategies. Of particular concern is that instructors might overestimate the degree to which they use strategies that they deem to be indicative of best practices. One piece of evidence that suggests that this tendency may not be widespread is that there was considerable variability in instructor reports, with mean ratings for many strategies (e.g., students design experiments) well below the scale midpoint. We believe that the concepts of lab and lecture are well understood and agreed upon by physics instructors despite the fact that, historically, they tend to be related to traditional teaching methods. To be inclusive of instructors who follow modern student-centered teaching methods (including minilectures interspersed with hands-on activities), quotation marks were used for the word lecture when the survey was offered.

A second limitation of the current study is that the survey relied on instructors' perceptions of student engagement. It is likely that instructors responded to the survey with different notions of what engagement means. This possibility is supported by the vast literature on student engagement which suggests that student engagement is multifaceted and that there is no agreed-upon definition. For instance, the 2016 Glossary of Education Reform definition states:

"In education, student engagement refers to the degree of attention, curiosity, interest, optimism, and passion that students show when they are learning or being taught, which extends to the level of motivation they have to learn and progress in their education."

Meanwhile, Bower [35] identifies four aspects of student engagement: (a) with the process of learning, (b) with the object of study, (c) with multidisciplinary contexts, and (d) with social and civic contexts, and Ashwin and McVitty [36] focus on degree of student involvement. Future research will be important in understanding how both IPLS instructors and their students conceptualize engagement in IPLS courses and in understanding whether any of the associations here reported may be better explained by unmeasured or confounding variables. For example, although instructors with more experience teaching introductory physics to students majoring in life science disciplines reported more confidence that their course effectively engages these students than instructors with less experience, it may be the level of experience is confounded with commitment to the teaching physics to nonscience majors or that level of experience covaries with perceptions of what "engagement" means. 


\section{ACKNOWLEDGMENTS}

Living Physics Portal project activities are supported by National Science Foundation Grant No. 1624185. The current study received additional support from the Science Education Resource Center (SERC) at Carleton
College. Survey design and administration were completed in collaboration with Robert Hillborn (AAPT), Sam McKagan (AAPT), Chandra Turpen (University of Maryland), Adrian Madsen (AAPT), and Edward Redish (University of Maryland).
[1] C. H. Crouch and K. Heller, Introductory physics in biological context: An approach to improve introductory physics for life science students, Am. J. Phys. 82, 378 (2014).

[2] D. C. Meredith and J. A. Bolker, Rounding off the cow: Challenges and successes in an interdisciplinary physics course for life sciences students, Am. J. Phys. 80, 913 (2012).

[3] E. Redish and D. Hammer, Reinventing college physics for biologists: Explicating an epistemological curriculum, Am. J. Phys. 77, 7 (2008).

[4] American Association for the Advancement of Science, Vision and Change in Undergraduate Biology Education: A Call to Action (American Association for the Advancement of Science Press, Washington, DC, 2011).

[5] Howard Hughes Medical Institute-American Association of Medical Colleges Committee, Scientific Foundations for Future Physicians (American Association of Medical Colleges, Washington, DC, 2009).

[6] Committee on Undergraduate Biology Education, National Research Council, BIO 2010: Transforming Undergraduate Education for Future Research Biologists (National Academies Press, Washington, DC, 2003).

[7] B. Alberts, The cell as a collection of protein machines: Preparing the next generation of molecular biologists, Cell 92, 291 (1998).

[8] C. H. Crouch, R. Hilborn, S. A. Kane, T. McKay, and M. Reeves, Physics for future physicians and life scientists: a moment of opportunity, APS News 19, 3 (2010).

[9] E. Redish, C. Bauer, K. L. Carleton, K. L., T. J., M. Cooper, C. H. Crouch, B. W. Dreyfus, B. D. Geller, J. Giannini, J. S. Gouvea, M. W. Klymkowsky, W. Losert, K. Moore, J. Presson, V. Sawtelle et al., NEXUS/Physics: An interdisciplinary repurposing of physics for biologists, Am. J. Phys. 82, 368 (2014).

[10] J. Watkins, J.E. Coffey, E. Redish, and T. J. Cooke, Disciplinary authenticity: Enriching the reforms of introductory physics courses for life-sciences students, Phys. Rev. ST Phys. Educ. Res. 8, 010112 (2012).

[11] American Association of Physics Teachers, Conference on Introductory Physics for the Life Sciences Report (American Association of Physics Teachers, College Park, MD, 2015).

[12] livingphysicsportal.org.

[13] E. Brewe, V. Sawtelle, L. H. Kramer, G. E. O’Brien, I. Rodriguez, I., and P. Pamelá, Toward equity through participation in Modeling Instruction in introductory university physics, Phys. Rev. ST Phys. Educ. Res. 6, 010106 (2010).

[14] S. Freeman, S. L. Eddy, M. McDonough, M. K. Smith, H. Okoroafor, H. Jordt, and M. Wendertoh, Active learning increases student performance in science, engineering, and mathematics, Proc. Natl. Acad. Sci. U.S.A. 111, 8410 (2014).

[15] E. A. Williams, J.P. Zwolak, R. Dou, and E. Brewe, Linking engagement and performance: The social network analysis performance, Phys. Rev. Phys. Educ. Res. 15, 020150 (2019).

[16] J. L. Docktor and J. P. Mestre, Synthesis of disciplinebased education research in physics, Phys. Rev. ST Phys. Educ. Res. 10, 020119 (2014).

[17] J. D. H. Gaffney and A. L. Gaffney, Student satisfaction in interactive engagement-based physics classes, Phys. Rev. Phys. Educ. Res. 12, 020125 (2016).

[18] D. E. Meltzer and D. K. Thornton, Resource Letter ALIP1: Active learning instruction in physics, Am. J. Phys. 80, 478 (2012).

[19] K. Miller, S. Zyto, D. Karger, G. Yoo, and E. Mazur, Analysis of student engagement in on online annotating system in the context of a flipped introductory physics class, Phys. Rev. Phys. Educ. Res. 12, 020143 (2016).

[20] K. Shar, R. Russ, and J. T. Laverty, Student epistemological framing on paper-based assessments, Phys. Rev. Phys. Educ. Res. 16, 020101 (2020).

[21] B. D. Geller, C. Turpen, and C. H. Crouch, Sources of student engagement in Introductory Physics for Life Sciences, Phys. Rev. Phys. Educ. Res. 14, 010118 (2018).

[22] A. Bandura, Self-efficacy mechanism in human agency, Am. Psychol. 37, 122 (1982).

[23] M. Zee and H. M. Y. Koomen, Teacher self-efficacy and its effects on classroom processes, student academic adjustment, and teacher well-being: A synthesis of 40 years of research, Rev. Educ. Res. 86, 981 (2016).

[24] A. W. Hoy, Self-efficacy in college teaching, Essays on Teaching Excellence: Toward the Best in the Academy, Prof. Org. Dev. Netw. Higher Edu. 15, 7 (2004).

[25] W. Condon, E. R. Iverson, C. A. Manduca, C. Rutz, and G. Willett, Faculty development and student learning: Assessing the connections, Scholarship of Teaching and Learning (Indiana University Press, Bloomington, IN, 2015).

[26] C. A. Manduca, E. R. Iverson, M. Luxenberg, R. H. Macdonald, D. A. McConnell, D. W. Mogk, and B. J. Tewksbury, Improving undergraduate STEM education: The efficacy of discipline-based professional development, Sci. Adv. 3, 2 (2017). 
[27] See Supplemental Material at http://link.aps.org/ supplemental/10.1103/PhysRevPhysEducRes.17.020133 for Survey items.

[28] J. Murray, Likert data: what to use, parametric or nonparametric?, Int. J. Bus. Soc. Sci. 11, 4 (2013).

[29] G. Norman, Likert scales, levels of measurement and the "laws" of statistics, Adv. Health Sci. Educ. Theory Pract. 15, 625 (2010).

[30] G. M. Sullivan and A. R. Artino, Analyzing and interpreting data from Likert-type scales, J. Grad. Med. Educ. 5, 541 (2013).

[31] J. Cohen, Statistical Power Analysis for the Behavioral Sciences, 2nd ed. (Laurence Erlbaum Associates, Hillsdale, NJ, 1988).

[32] E. Agra, S. M. Fischer, and S. L. Beilock, The role of students' gender and anxiety in physics performance, in Proceedings of the 2017 Physics Education Research Conference, Cincinnati, OH (AIP, New York, 2017).

[33] A. Hobson, Combating "science anxiety" in the classroom, APS News 7, 9 (1998).

[34] D. Hemingway, M. Eichenlaub, W. Losert, and E. Redish, Examining student attitudes in introductory physics via the math attitude and expectations survey (MAX), APS April Meeting Abstr. 2017, F1. 025 (2017).

[35] S. Bower, Engaged learning: Are we all on the same page?, Peer Review 7, 4 (2005).

[36] P. Ashwin and D. McVitty, The meanings of student engagement: implications for policies and practices, in The European Higher Education Area, edited by A. Curaj, L. Matei, R. Pricopie, J. Salmi, and P. Scott (Springer, Cham, 2015). 